\title{
Changes in thermal discomfort indices in Romania and their connections with large-scale mechanisms
}

\author{
Andreea Dobrinescu ${ }^{1,2}$, Aristita Busuioc ${ }^{1, *}$, Marius-Victor Birsan ${ }^{1}$, \\ Alexandru Dumitrescu ${ }^{1}$, Alina Orzan ${ }^{1}$
}

\author{
${ }^{1}$ National Meteorological Administration, Sos. Bucuresti-Ploiesti 97, Sect. 1, Bucharest 013686, Romania \\ ${ }^{2}$ University of Bucharest, Faculty of Physics, PO Box MG-11, Bucharest, Romania
}

\begin{abstract}
We analysed changes in variability characteristics for 2 indices quantifying winter (WCT: wind chill equivalent temperature chart index) and summer (THI: temperature-humidity index) thermal stresses at a high spatial resolution across Romania for the period 1962-2010. The linear trends, and shifts in the mean and main modes of variability were examined using nonparametric tests (Mann-Kendall and Pettitt) and empirical orthogonal function (EOF) analysis. The physical mechanisms responsible for the identified characteristics of variability were examined through canonical correlation analysis (CCA). The results showed a significant upward trend for both indices over the entire country, except for some areas for WCT, with a significant upward shift around the year 1987 for winter and 1985 for summer. A strong increase in the frequency of extremely high THI values was revealed, indicating an increased risk to human health during summers in Romania after 1985. However, the upward trend in WCT would indicate a decreased risk of human health during winters in Romania after 1987. The main large-scale mechanism responsible for the spatial and temporal behaviour of the 2 stress indices was given by the first CCA pair, showing that the increasing trend was mainly explained by the increasing trend in the temperature at $850 \mathrm{hPa}$ covering Romania simultaneously with an increasing trend in zonal circulation (WCT) and an increasing trend in specific humidity at $700 \mathrm{hPa}$ (THI). On a decadal/multidecadal time scale, the variations in the 2 indices are modulated by the North Atlantic Oscillation (winter) and the Atlantic Multidecadal Oscillation (summer).
\end{abstract}

KEY WORDS: Thermal stress indices $\cdot$ Trends $\cdot$ Shifts $\cdot$ Nonparametric tests $\cdot$ Empirical orthogonal functions $\cdot$ Canonical correlation analysis $\cdot$ Romania

\section{INTRODUCTION}

Many studies support the conclusion that most analysed global land areas have experienced a significant increase in temperature extremes since around 1950 (e.g. Alexander et al. 2006, Orlowsky \& Seneviratne 2012, Donat et al. 2013), while the cold extremes have decreased. One of the main reasons for this phenomenon, besides natural factors, is related to global warming due to increasing greenhouse gas concentrations. Several high-profile heat waves have occurred in recent years, e.g. in Europe in 2003
(Beniston 2004, Chase et al. 2006), Russia in 2010 (Dole et al. 2011, Trenberth \& Fasullo 2012) and the USA in 2011/2012 (Hoerling et al. 2012), each of which had severe effects.

Generally, most studies on temperature extremes have considered several indices based on maximum, minimum or daily temperatures (frequency, duration, intensity and heat waves). However, some more complex indices associated with climate extremes depend on 2 meteorological variables; these indices include Palmer drought indices (Palmer Drought Severity Index [PDSI] and the self-calibrating PDSI; 
Palmer 1965, van der Schrier et al. 2006), and the Standardised Precipitation Evapotranspiration Index (SPEI), all of which are based on temperature and precipitation data (Vicente-Serrano et al. 2010). Other indices quantifying the direct discomfort felt by the human body, such as the heat index based on air temperature and relative humidity (temperature-humidity index: THI) and cold index (wind chill equivalent temperature chart index: WCT) based on air temperature and wind speed, usually called thermal stress indices, have thus far been less analysed from the climatological point of view (in terms of trends and mechanisms controlling their variability), even though they are indicators of factors that can have serious impacts on human health. Information about long-term changes in thermal stress indices is of great social importance, in terms of understanding the effects of such changes on society (e.g. human health). Various thermal stress indices have been defined (e.g. Spagnolo \& De Dear 2003, Osczevski \& Bluestein 2005, Dikmen \& Hansen 2009, Sherwood \& Huber 2010, Nastos \& Matzarakis 2012, Mohan et al. 2014). The main climate parameters involved in their definition are air temperature, relative humidity and wind speed. Other more complex thermal indices are based on human energy balance, such as the Physiologically Equivalent Temperature and Universal Thermal Climate index (Nastos \& Matzarakis 2012). Usually, thermal stress indices are defined separately for winter and summer.

Most studies on temperature extremes have revealed various large-scale circulation indices/ patterns as the main drivers of their variability at inter-annual to decadal/multidecadal time scales. The best known are the El Niño-Southern Oscillation and Pacific Decadal Oscillation (PDO) for the Northern Hemisphere (Kenyon \& Hegerl 2008), and for Europe, the strongest influence is given by the North Atlantic Oscillation (NAO), especially in winter (e.g. Hurrell \& van Loon 1997, Bojariu \& Paliu 2001). Other large-scale atmospheric circulation patterns in the Euro-Atlantic domain (Arctic Oscillation, Mediterranean Oscillation) together with more regional patterns (Scandinavian, Central European, East European and East Atlantic) have been studied to examine possible connections with climate extremes for European sub-regions (e.g. Tomozeiu et al. 2002, Efthymiadis et al. 2011, Birsan et al. 2014). On a multidecadal time scale, European extremes have been shown to be influenced by the Atlantic Multidecadal Oscillation (AMO; Della-Marta et al. 2007, Gámiz-Fortis et al. 2011, Ionita et al. 2013).
Various statistical techniques have been used to establish connections between circulation patterns/ indices and regional climate extremes, starting from the simplest ones such as simple correlations (e.g. Efthymiadis et al. 2011) or composite maps (e.g. Tomozeiu et al. 2002, Ionita et al. 2013) to multivariate techniques such as canonical correlation analysis $\left(\mathrm{CCA}_{\text {; }}\right.$ e.g. Zorita et al. 1992, Busuioc et al. 2001, 2015, Haylock \& Goodess 2004, Xoplaki et al. 2004, Della-Marta et al. 2007). CCA seems to be more adequate for reproducing the complexity of the mechanisms controlling regional climate variability, and was also used in the present study.

In Romania, previous studies have analysed variability in temperature extremes (e.g. Tomozeiu et al. 2002, Busuioc \& Tomozeiu 1998, Busuioc et al. 2010, Dumitrescu et al. 2014), but most of them used a limited number of stations or short intervals for analysis or did not discuss the details of the mechanisms controlling the variability in the extremes. In a recent paper by Busuioc et al. (2015), 6 temperature extremes based on maximum and minimum temperatures (quantifying their intensity, frequency and duration), computed at a high spatial resolution (85 stations) for the 1961-2010 period were analysed, to identify the main spatial/temporal characteristics of their (simultaneously with the variability in precipitation extremes), on the one hand, and to understand the large-scale mechanisms responsible for this variability on the other hand.

The purpose of the present study was to analyse the long-term changes in 2 thermal stress indices across Romania using all stations with complete data records over the period 1962-2010. The thermal discomfort indices analysed in this study are among those presented by previous studies (e.g. Osczevski \& Bluestein 2005, Teodoreanu \& Bunescu 2007, Dikmen \& Hansen 2009) or recommended by WMO (2004). The long-term trends and shifts in the means, as well as the large-scale mechanisms responsible for this behaviour were analysed. This study is a first step in developing skilful statistical downscaling models to project future changes in thermal discomfort indices at a high spatial resolution across Romania that can be used in impact studies. These types of models are still necessary considering the low skill of the regional climate models (RCMs) in reproducing some climate parameters involved in the definition of the thermal stress indices, such as wind speed. Details on the methodology are provided in Section 2, the main findings are presented in Section 3, and our conclusions are summarized in Section 4. 


\section{DATA AND METHODS}

\subsection{Data}

Using hourly/daily data of air temperature, relative humidity and wind speed recorded at all weather stations in Romania, with complete data records over the period 1962-2010, 2 indices that quantify heat stress were computed: the warmrelated THI, computed for the summer season at 87 meteorological stations, and the cold-related WCT, computed for winter at 61 meteorological stations. The names and locations of the stations used in this study are presented in Fig. 1. The THI was computed based on hourly measurements to better capture the 'dangerous' values (see the THI definition below), while the WCT was based on daily data since, for the most part, the latter were a priori quality controlled using MASH software (Szentimrey 1997). The daily wind speed values were additionally homogenized using the same software. The winter (WCT) and summer (THI) averages were then computed and their time series were further analysed as presented in Section 3.
THI uses air temperature and relative humidity to estimate an apparent temperature, i.e. the one felt by the human body. Normally, the body is cooled by perspiration, a process during which the water is evaporated, and as a result, the retained heat is reduced. When relative humidity is high, the water evaporation rate is reduced. This means a slower cooling of the body, which retains more heat than in dry air conditions. The THI is defined as:

$$
\begin{gathered}
\mathrm{THI}=\left(\mathrm{T}_{\mathrm{A}} \times 1.8+32\right)-(0.55-0.55 \times \mathrm{RH} / 100) \\
\times\left(\mathrm{T}_{\mathrm{A}} \times 1.8-26\right)
\end{gathered}
$$

where $\mathrm{T}_{\mathrm{A}}$ is air temperature $\left({ }^{\circ} \mathrm{C}\right)$ and $\mathrm{RH}$ is relative humidity. The critical threshold above which the human body feels strong discomfort is 80 units (Table 1). This index was presented by Teodoreanu \& Bunescu (2007) and is one of the 9 indices suggested by Dikmen \& Hansen (2009). The spatial average (geographically across the country, over the entire period 1962-2010) of the occurrence probability for THI > 80 units is $6 \%$, with large regional differences (lower probabilities in the intra-Carpathian region and higher probabilities in extra-Carpathian regions; 0 probability in the mountain region). The summer

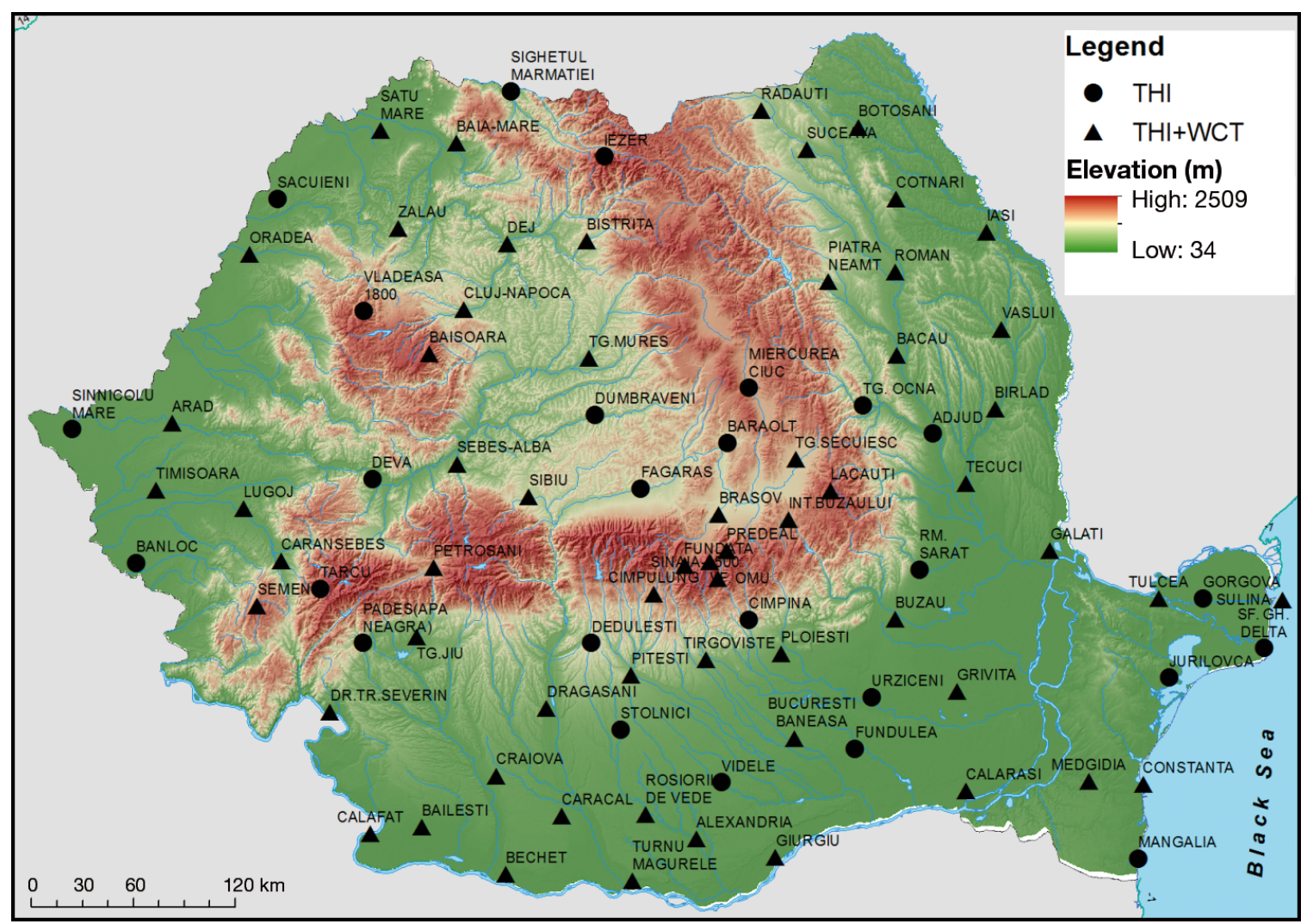

Fig. 1. Names and locations of the stations used in this study. The stations common for both indices are marked by triangles, while those related only to the temperature-humidity index (THI) are marked by circles. WCT: wind chill equivalent temperature chart index 
Table 1. Classification of the wind chill equivalent temperature chart index (WCT) and the temperature-humidity index (THI) in terms of the discomfort felt by the human body. Usually, the WCT is expressed in temperature-like units $\left({ }^{\circ} \mathrm{C}\right)$, but it is not a temperature; rather, it only expresses a human sensation and likens the way human skin perceives the temperature on a calm day. The THI is expressed in dimensionless units

\begin{tabular}{|lcc|}
\hline Index & Comfort class & Condition \\
\hline 1 & Severe danger from cold & WCT $\leq-35^{\circ} \mathrm{C}$ \\
2 & Extremely cold & $-35^{\circ} \mathrm{C}<\mathrm{WCT} \leq-20^{\circ} \mathrm{C}$ \\
3 & Uncomfortably cold & $-20^{\circ} \mathrm{C}<\mathrm{WCT} \leq 0^{\circ} \mathrm{C}$ \\
4 & Uncomfortably hot & $66 \leq \mathrm{THI}<80$ \\
5 & Severe danger from heat & $\mathrm{THI} \geq 80$ \\
\hline
\end{tabular}

(June to August) frequency of THI $\geq 80$ units (Fr-THI) in each year was also computed.

For the winter season, we used the WCT presented by Osczevski \& Bluestein (2005) and also recommended by WMO (2004), expressed by the relationship:

$$
\begin{gathered}
\mathrm{WCT}=13.12+0.6215 \times \mathrm{T}_{\mathrm{A}} \\
-11.37 \times \mathrm{FF}_{10} 0.16+0.3965 \mathrm{~T}_{\mathrm{A}} \times \mathrm{FF}_{10} 0.16
\end{gathered}
$$

where $\mathrm{T}_{\mathrm{A}}$ is the air temperature $\left({ }^{\circ} \mathrm{C}\right)$ measured at a standard level $(2 \mathrm{~m})$, and $\mathrm{FF}_{10}$ is the wind speed $(\mathrm{km}$ $\mathrm{h}^{-1}$ ) measured at $10 \mathrm{~m}$. In this study, the WCT was computed for the wind speed projected at $2 \mathrm{~m}$ using the relationship $\mathrm{FF}_{2}=\mathrm{FF}_{10} \times 0.75$ (Allen et al. 1998), in order to have both meteorological variables measured at the same level $(2 \mathrm{~m})$. The WCT thresholds for various human sensations are presented in Table 1.

The large-scale predictor data (air temperature at $850 \mathrm{hPa}$ : T850; sea level pressure: SLP; specific humidity at $700 \mathrm{hPa}$ : SH700) were downloaded from the NCEP / NCAR database (Kalnay et al. 1996) for the same period as local thermal indices (1961-2010), in a spatial grid of $2.5^{\circ} \times 2.5^{\circ}$.

\subsection{Methods}

We computed the long-term linear trends of the THI and WCT over 1962-2010. The nonparametric Mann-Kendall (MK; Mann 1945, Kendall 1975, Sneyers 1975, Kulkarni \& von Storch 1995) and Pettitt (Pettitt 1979) tests were used to test the statistical significance of the linear trend and shifts in the mean of the time series analysed in this study. Changes in the relative frequency of 'dangerous' values for THI (using the Fr-THI) induced by the shift in the mean were also estimated. Spatial and temporal variability modes were identified by the empirical orthogonal function (EOF) technique (Wilks 1995, von Storch \& Zwiers 1999). The EOF analysis is a multivariate statistical method whose main purpose is to reduce the dimensionality of a multivariate data set by transforming the original variables in a new set with considerably fewer variables, which is able to contain the variability signals of the original data set. The EOF technique removes the climate noise and retains most of the climate signal of large data sets. The first 2 EOF patterns (hereafter referred to as EOF1 and EOF2) and their associated time series (referred to as PC1 and PC2) are the most important. Because EOF1 explains most of the observed variance, it represents the primary spatial variability mode of the analysed data set, while the main temporal variability mode (trends, shifts, etc.) is summarized by PC1.

The large-scale mechanisms controlling the variability of the 2 thermal stress indices in Romania were analysed using CCA (e.g. Barnett \& Preisendorfer 1987, Zorita et al. 1992, Busuioc \& von Storch 1996, Busuioc et al. 2001) applied between the spatial vectors associated with anomalies of the 2 indices (WCT and THI) and spatial vectors associated with anomalies of the large-scale predictors (T850, SLP and SH700). The large-scale predictors were considered either separately or in combination and represent dynamic (SLP) or thermodynamic factors (T850, SH700). When a combination of 2 or more predictors is used, their time series are first standardised by dividing the anomalies (deviation from the long-term mean) by the standard deviation. The standardised anomalies for each spatial predictor, in each season of the year, are then concatenated in a single spatial vector, hereafter referred to as combined predictors. This technique was proven - in a recent study on other climate extremes (temperature and precipitation) in Romania (Busuioc et al. 2015) — to be adequate in reproducing the complexity of the mechanisms controlling the regional climate variability, yielding more coherent mechanisms from the physical point of view. The CCA technique was also presented by Zorita et al. (1992), Xoplaki et al. (2004) and Della-Marta et al. (2007). Through CCA, the optimum linear combination for 2 multi-dimensional vectors (the predictand, i.e. thermal stress indices, and the predictor, i.e. the large-scale variables) and pairs of patterns are selected so that their associated time series are maximally correlated. Through the way it is constructed, the CCA method allows a physical interpretation of the mechanism controlling the variability of the regional climate parameters (see Busuioc \& von Storch 1996, Busuioc et al. 2001, 2015). Before the CCA, the predictors and predictands are 
projected onto their EOF space, and the most important ones (explaining most of the variance) are retained in the CCA. The CCA pairs are ranked in terms of magnitude of the canonical correlation coefficient between the time series associated with the CCA pairs (the first CCA pair showing the highest correlation coefficient, followed by the second one and so on), and not in terms of explained variance of the CCA pair patterns. To find the main mechanism controlling the local thermal stress indices in Romania, the optimum combinations of EOFs were considered in the CCA, so that (1) the explained variance of the predictor/predictand in the first CCA pair is as large as possible; (2) the predictand CCA pattern is as similar to its EOF1 pattern as possible and explains about the same variance; and (3) its associated time series has, as much as possible, the same characteristics of variability (similar trend rate and shift in the mean) as PC1 of the selected predictand. Thus, if the predictor-predictand connection represented by this CCA pair is strong (high canonical correlation coefficient) and shows a reasonable mechanism from the physical point of view (as will be presented in Section 3.3), the similarity in the shifts of the time series associated with this CCA pair would give more confidence to stating that there could be a physical connection between the 2 signals, and that this mechanism could be responsible for the main variability mode of the predictand. This type of mechanism was presented by Busuioc \& von Storch (1996) in the explanation of winter precipitation change at 14 stations in Romania over the interval 1901-1987, with the SLP being considered as the predictor. Similar plausible mechanisms were later found by Busuioc et al. (2001) for monthly precipitation in Sweden and by Xoplaki et al. (2004) for precipitation variability in the wet Mediterranean season. In a recent paper by Busuioc et al. (2015), this technique was refined for combinations of more predictors/predictands, while in the present study, we used complex predictands (thermal stress indices) based on 2 climate variables.

\section{RESULTS}

\subsection{Linear trends of thermal stress indices}

Fig. 2a,b shows the linear trends of the 2 stress indices (THI, WCT) over the period 1962-2010. Before computing the trend, the original values were standardised to allow them to be compared with each other, as well as with trends of other climate variables (e.g. mean air temperature). An upward trend was revealed for both indices but was statistically significant ( $5 \%$ level) over the entire country only for THI and over a restricted area for WCT (mainly in eastern and mountainous areas); a downward trend (though not statistically significant at the $5 \%$ level) was evident for WCT for some isolated points, located in the intraCarpathian and southwestern regions. The WCT trend behaviour was roughly similar to the behaviour of the winter mean temperature (denoted by ' $\mathrm{TT}^{\prime}$ ) trend (Busuioc et al. 2010) showing the TT contribution to the WCT variability. However, some differences were revealed: the winter TT exhibited an upward trend over the entire country but was statistically significant only over some extra-Carpathian regions. This result could be explained by the additional influence of the wind speed variability upon the WCT variability. According to the results presented by Birsan et al. (2013), the wind speed trend in winter is a decreasing one over the entire country but is statistically significant only in the extra-Carpathian regions. The WCT trend rate was lower than the TT rate (see Fig. S1 in the Supplement at www.int-res.com/articles/suppl/ c064p213_supp.pdf), except for a large area in the southeastern part where the WCT trend rate was higher than the TT rate.

For THI, the highest rate of change was revealed in the southeastern part (the Black Sea coast excepted) and also in the eastern and central areas (Fig. 2b). This behaviour is mostly similar to the behaviour of the summer mean temperature trend (Busuioc et al. 2010), showing the prevalent air temperature contribution in THI variability, with some small regional differences: a higher rate for THI in the central part and a higher rate of the summer temperature in the southwestern part. This behaviour could be related to the reduced change rate of the relative humidity, as was shown by the linear trend of the summer relative humidity, showing no significant linear trend except for a small area of upward trend over the southwestern mountain area and a small area of downward trend in the intra-Carpathian region (see Fig. S2 in the Supplement). As a consequence, the THI trend magnitude is similar to that of the summer mean temperature trend.

The Pettitt test revealed a significant upward shift (5\% significance level) around 1987 for WCT and 1985 for THI. This shift induced changes in the relative frequency of the extremes ('dangerous' values for human health) of the 2 indices. In this paper, we analysed the extremely high THI values $(\geq 80)$ in summer. Since the time series associated with these events (Fr-THI) exhibits many 0 values, producing 


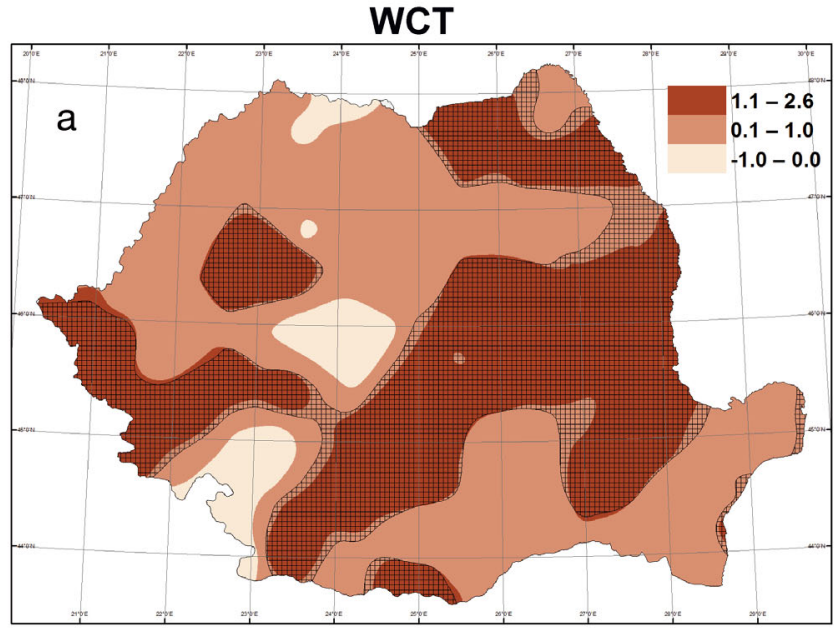

Fr-THI: (1986-2010)-(1962-1985)

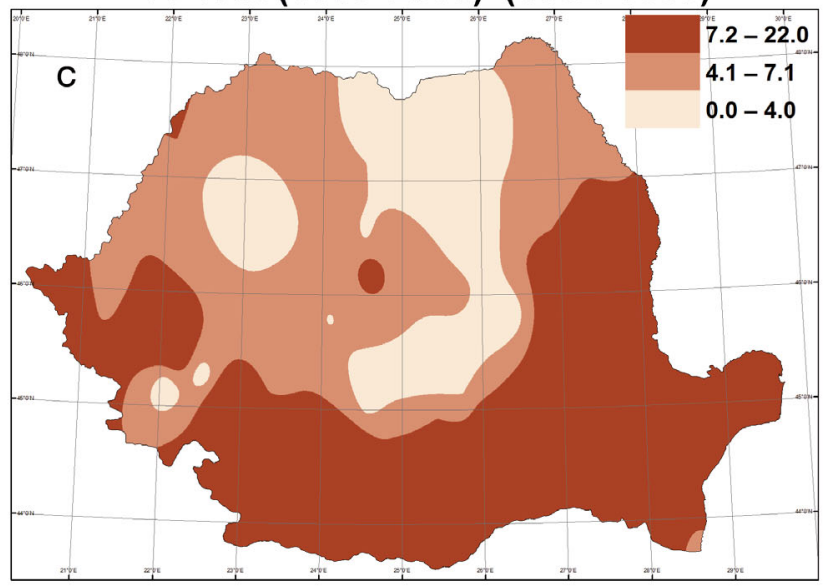

difficulties in the application of usual statistical tests, the differences between the relative frequency (empirical occurrence probability) computed over the 2 subintervals induced by the statistically significant shifts in the mean (mentioned above) were calculated (Fig. 2c). A strong increase in the frequency of extremely high THI was revealed, with the highest values $(>7 \%)$ covering the southern, southwestern and southeastern areas.

\subsection{Spatial variability characteristics of thermal stress indices}

As presented in Section 2, the main characteristics of the spatial and temporal variability for the 2 indices (WCT and THI) are summarized by the EOF analysis. For both indices, a small number (6-8) of variability modes (EOF patterns) explaining $>1 \%$ of the total variance were found. The first pattern explains a significant percentage of the observed vari-

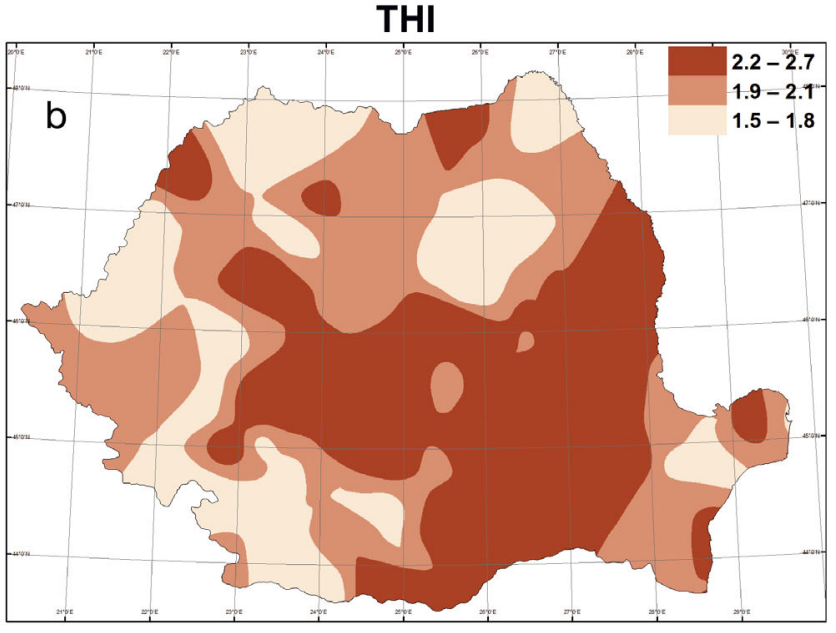

Fig. 2. Long-term linear trends of the standardised thermal stress indices over the period 1962-2010. (a) Wind chill equivalent temperature chart index (WCT); only the crosshatched area is statistically significant at the $5 \%$ level. (b) Temperature-humidity index (THI); values are statistically significant at the $5 \%$ level over the entire country. (c) Differences between the relative frequency of the dangerous values for the summer thermal stress index (THI $\geq 80$ ) over the 2 sub-intervals induced by the corresponding shifts in the mean (1985)

ance of these indices: $89 \%$ for THI and $73 \%$ for WCT. PC1 exhibits a statistically significant upward trend (with a higher rate for THI) for both indices, with a shift around 1985 for THI and 1987 for WCT (Fig. 3). We found that the first EOF pattern (Fig. 3) for both indices presents the same sign over the entire country, suggesting that the variability of these indices is controlled by a large-scale mechanism, which will be examined in Section 3.3. A relatively homogeneous spatial variability (e.g. anomaly intensity) is shown by THI (Fig. 3b), as opposed to WCT, where the spatial differences in the anomaly intensity are more marked (higher values in the eastern areas; Fig. 3a). The second EOF (not shown) exhibits a dipole pattern with some differences between the 2 stress indices: a NE-SW-oriented gradient for THI and an intra/extra-Carpathian pattern for WCT. The variance explained by this pattern is between $3 \%$ (THI) and $7 \%$ (WCT). This result shows the influence of regional factors (topography) on the variability of the winter index. 

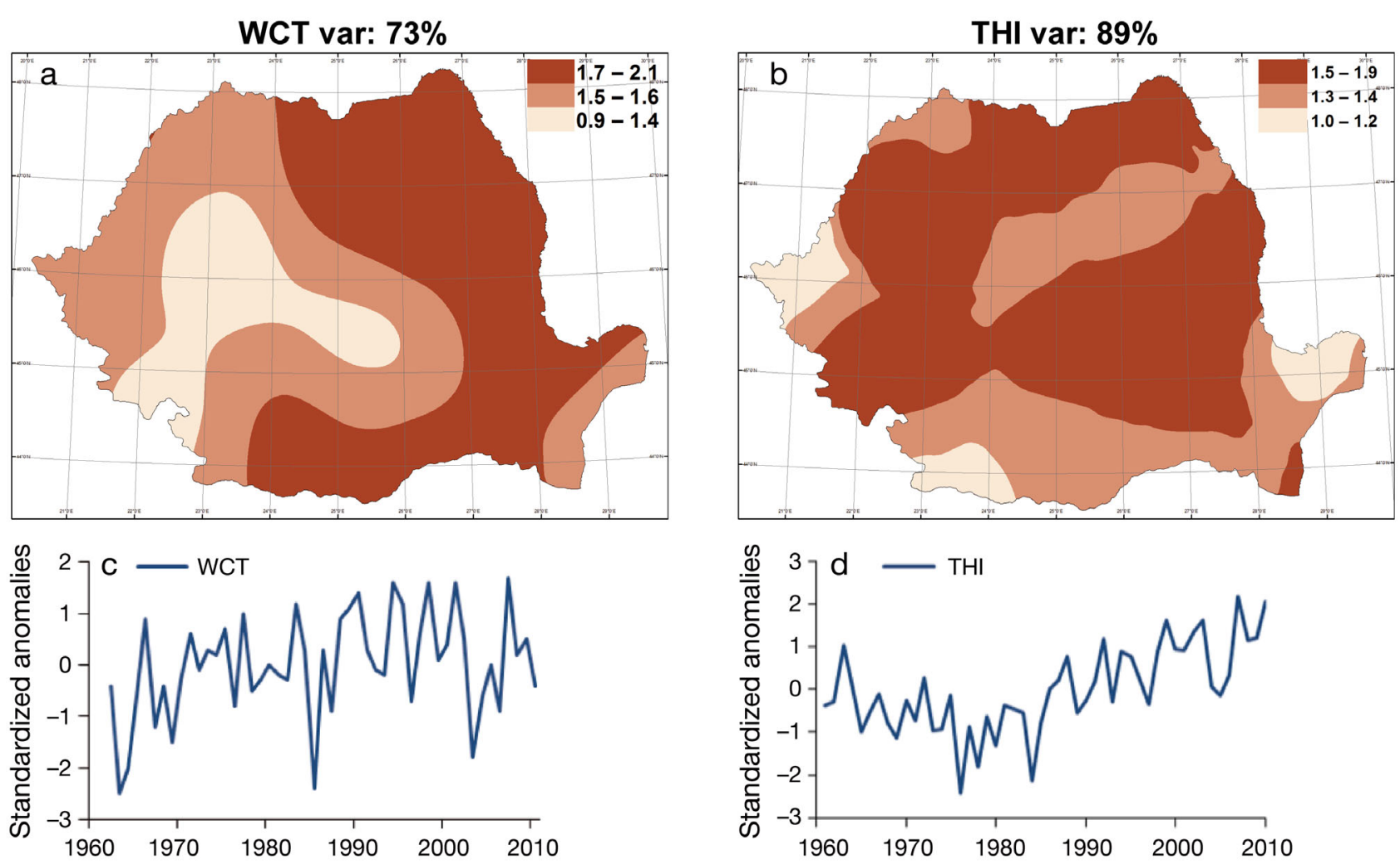

Fig. 3. First empirical orthogonal function (EOF) pattern for (a) the wind chill equivalent temperature chart index (WCT) and (b) the temperature-humidity index (THI) computed over the period 1962-2010; the explained variance is included. Also shown are PC1 (standardized anomalies) for (c) WCT and (d) THI

\subsection{Connection between WCT and THI anomalies and large-scale climate anomalies}

As mentioned in Section 2, the CCA method identifies pairs of spatial patterns (predictor-predictand) whose associated time series are optimally correlated. Considering the fact that the 2 stress indices (WCT, THI) are based on air temperature, the T850 was first selected as a predictor, as it has been shown to be the best one for various temperature extremes (e.g. Busuioc et al. 2015). However, the definitions of the 2 indices (see Section 2.1) suggest taking into account other large-scale variables such as SLP for WCT and SH700 for THI. The large-scale area between $5^{\circ}-45^{\circ} \mathrm{E}$ and $35^{\circ}-55^{\circ} \mathrm{N}$, which proved to be an optimum predictor area for various climate parameters (including extremes) in previous papers (e.g. Busuioc et al. 1999, 2006, 2015), was considered. The predictors used in CCA were considered either separately (T850, SLP) or combined: T850 and SLP for WCT, T850 and SH700 for THI (see details in Section 2.2 for the definition of combined predictors).

The first 2 CCA pairs representing the connection between T850 and WCT are presented in Fig. S3a in the Supplement. The first CCA pair associates posi- tive T850 anomalies $\left({ }^{\circ} \mathrm{C}\right)$ showing above-normal temperature at $850 \mathrm{hPa}$ over almost the entire area (34\% explained variance) with the nucleus covering all of Romania, to above-normal WCT values (positive anomalies, ${ }^{\circ} \mathrm{C} ; 69 \%$ explained variance), similar to WCT EOF1 (with slightly less explained variance, $69 \%$ vs. $73 \%$ ). This mechanism seems to be plausible from a physical point of view: an above-normal air temperature at $850 \mathrm{hPa}$, inducing above-normal surface temperature, appears physically plausible to associate with a human sensation of warmth. The CCA1 pattern of WCT (Fig. S3a, top left), showing the highest anomalies over the eastern regions, is not similar to the CCA1 pattern of T850 as was expected (Fig. S3a, bottom left); the T850 CCA1 mainly exhibits a north-south gradient over the Romanian area and is more similar to the T850 EOF2 (not shown, $31 \%$ explained variance); the T850 EOF1 (not shown) shows a dipole structure with a NW-SE gradient (44\% explained variance). This result suggests that variability in the WCT is not controlled by the main mode of the T850 variability over the selected area. The time series associated with this pair show a very strong connection (correlation coefficient of 0.92) and exhibit a significant increasing trend with a 
similar upward shift around 1987, similar to the WCT PC1. This result indicates that the increasing trend of WCT could be explained by the increasing trend of the T850 field covering Romania, but the spatial distribution of the WCT trend magnitude cannot be justified by this connection, which warrants the inclusion of an additional predictor as presented below. The second CCA pair also shows a significant connection (correlation of 0.64) and associates a dipole T850 structure (with a north-south gradient, Romania being placed within the slightly negative area, near the zero line) with negative WCT anomalies in the intra-Carpathian region and positive ones in extra-Carpathian regions (probably influenced by the positive T850 anomalies covering the area north of Romania). The T850 CCA2 is a degenerated version of the T850 EOF1 representing a pattern with the gradient oriented NW-SE. This result again suggests that the T850 CCA2 pattern cannot completely justify the WCT CCA2 pattern in terms of the anomaly sign distribution that motivates the inclusion of an additional predictor, and this is given by the dynamic factor (surface atmospheric circulation) represented by the SLP anomalies.

Fig. $4 \mathrm{a}-\mathrm{d}$ presents the first 2 CCA pairs of connections between the T850-SLP combination and WCT. This connection is stronger than those obtained when the T850 alone is considered as a predictor, especially for CCA2, showing the additional importance of the SLP variability in WCT variability (correlation of 0.92 for CCA1 and 0.76 for CCA2). The T850 and WCT patterns of the CCA1 pair are also similar to those obtained when the T850 alone is considered as a predictor but with the nucleus of the highest T850 positive anomalies centred over Romania. The simultaneous variability of the T850 and SLP explains $26 \%$ of the total variance, while WCT explains $71 \%$, similar to WCT EOF1 (73\%). The SLP pattern shows a zonal circulation transporting a warmer Atlantic air mass to Romania; this air mass overlaps the warmer air mass over all of Romania induced by the positive T850 anomalies. The Western Plain is first affected and then, due to the obstacle presented by the Carpathians, the extra-Carpathian regions are affected, mainly the eastern part. This mechanism explains the highest positive WCT anomalies in eastern part, followed by the Western Plain, which cannot be justified when only the T850 is considered as a predictor (see Fig. S3a). The CCA1 SLP pattern is quite similar to the CCA1 SLP pattern when only SLP is considered as a large-scale predictor (see Fig. S3b, left column) showing a similar atmospheric circulation over Romania; the CCA1 WCT pattern is also similar to those presented above for combined predictors. This result confirms the important role of the dynamic factor (atmospheric circulation) in the spatial distribution of the WCT anomalies. The time series associated with the WCT CCA1 pattern exhibits characteristics similar to those presented above for WCT PC1 (compare Fig. 4e to Fig. 3c), i.e. mainly a significant upward trend with an upward shift around 1987, simultaneous with the time series associated with the (SLP+T850) CCA1 pattern. When the SLP alone is considered as a predictor, the 2 time series associated with the CCA1 pair do not exhibit a similar shift (around 1987 for WCT and 1973 for SLP).

Therefore, even if the T850 alone could explain the observed WCT temporal variability in Romania (general trend), only the combination between the SLP and T850 in the mechanism revealed by the connection represented by the first CCA pair (presented above) can better explain the spatial pattern of the WCT trend (including the magnitude) and the shift in the WCT variability. The correlation (Spearman) between the CCA1 time series and NAO index presents a statistically significant correlation (0.47), showing the NAO modulation on the WCT variability at a decadal time scale. This correlation is also significant when the trend is removed from both time series, showing a true connection. The second CCA pair (correlation coefficient of 0.76 ) also shows a plausible physical mechanism: slightly positive T850 anomalies over Romania (inducing a slightly warmer air mass over Romania) with simultaneous bipolar SLP structure $(19 \%$ explained variance, inducing anticyclonic southeastern circulation mainly influencing the eastern part of Romania; western Romania is influenced by the cyclonic southern circulation) are associated with positive WCT anomalies in the intraCarpathian regions and negative ones over the extraCarpathian regions (with the highest magnitude over the eastern regions; $4 \%$ explained variance). The negative WCT anomalies over the extra-Carpathian regions are induced by the anticyclonic southeastern circulations transporting a drier and colder air mass, which leads to air temperatures lower than the pre-existing ones due to the positive T850 anomalies, with the most affected being the eastern regions. The intra-Carpathian areas are protected by the Carpathian Mountains.

The predictor patterns of the 2 CCA pairs are not similar to the patterns of their first 2 EOFs (not shown), indicating that the mechanisms controlling the WCT variability are given by regional patterns of the combination between the thermodynamic (T850) and dynamic (SLP) factors. 

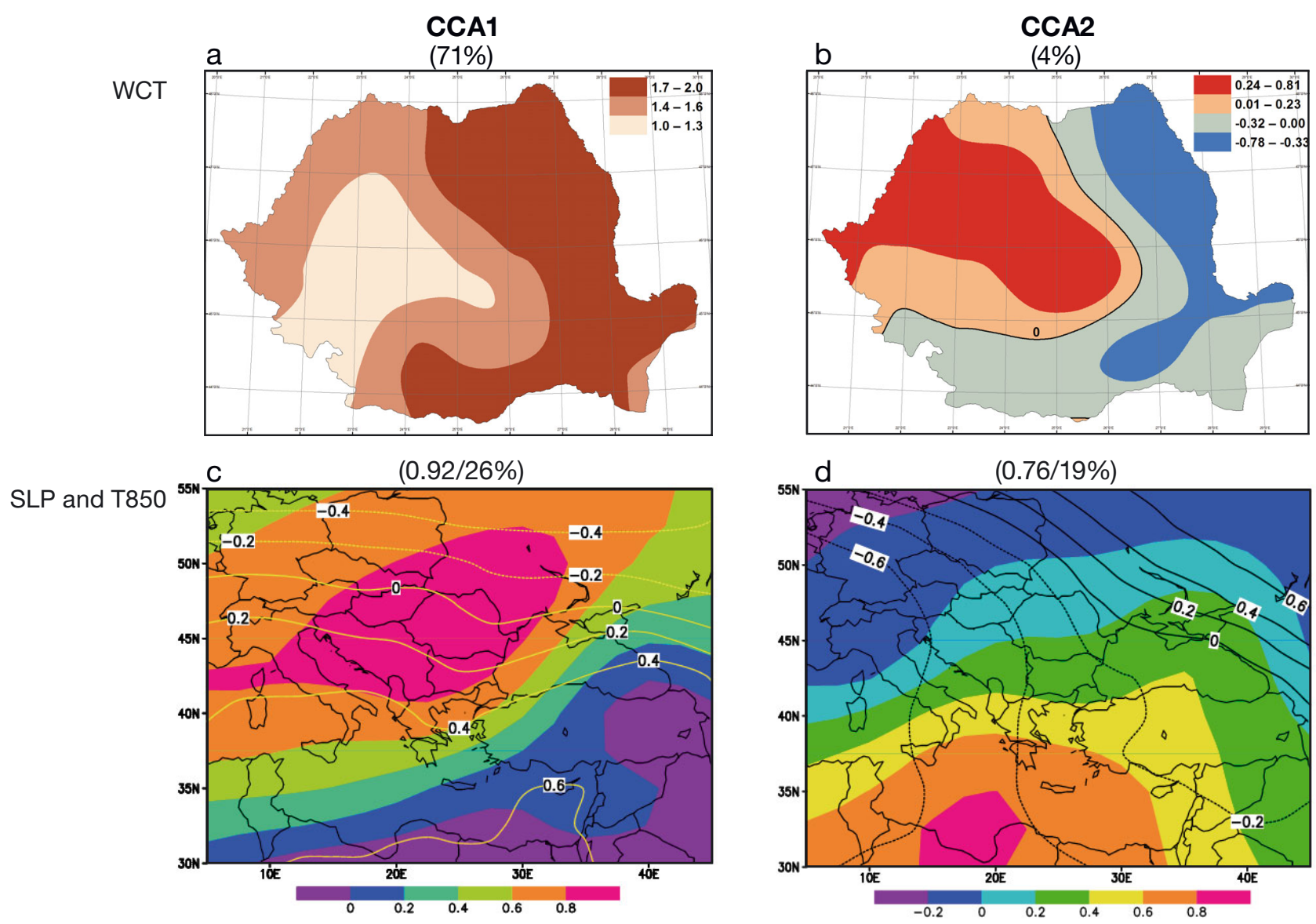

CCA time series
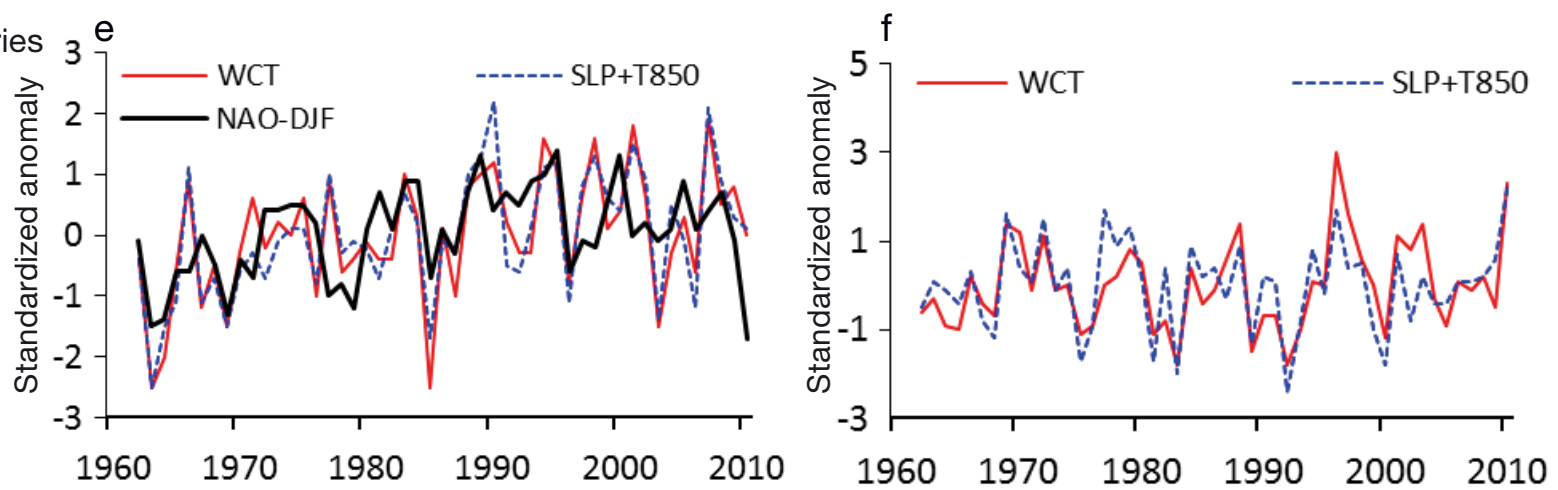

Fig. 4. Patterns of the first 2 canonical correlation analysis (CCA) pairs (left: CCA1, right: CCA2) of the combined predictors and wind chill equivalent temperature chart index (WCT) in winter. $(a, b) W C T$; parentheses above panels: explained variance. $(\mathrm{c}, \mathrm{d})$ Sea level pressure (SLP [hPa]; contours) and air temperature at $850 \mathrm{hPa}\left(\mathrm{T} 850,{ }^{\circ} \mathrm{C} ;\right.$ colours); parentheses above panels: canonical correlation coefficient/explained variance. (e,f) Time series (standardized anomalies) associated with the first 2 CCA pairs of the combined predictors (T850+SLP) and WCT. For the CCA1 time series (left), the NAO index is also included

Regarding the THI index, similar to WCT, CCA was performed between THI and T850 as well as between THI and the T850-SH700 combination; the patterns of the first 2 CCA pairs are presented in Fig. S4 in the Supplement and in Fig. 5a-d, respectively. The mechanisms related to the connection between T850 and THI (Fig. S4) are similar to those presented above for WCT, the positive T850 anomalies being associated with positive THI anomalies. The connection is very strong (correlation of 0.93 for CCA1 and 0.75 for CCA2). The time series associated with the CCA1 pair exhibit a significant increasing trend with a shift around 1985 for THI (similar to THI PC1) and around 1990 for T850. The THI CCA1 pat- 

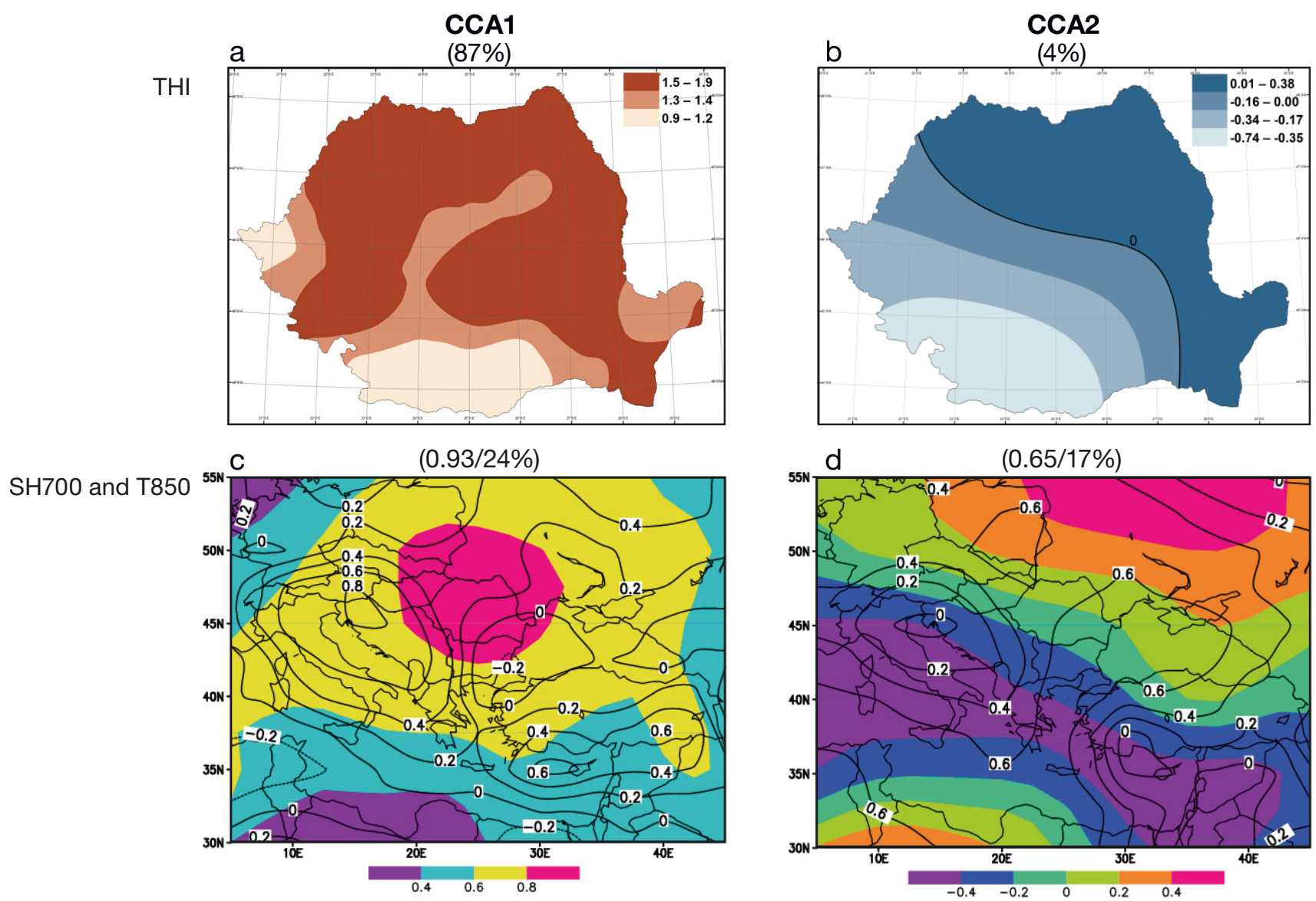

CCA time series e
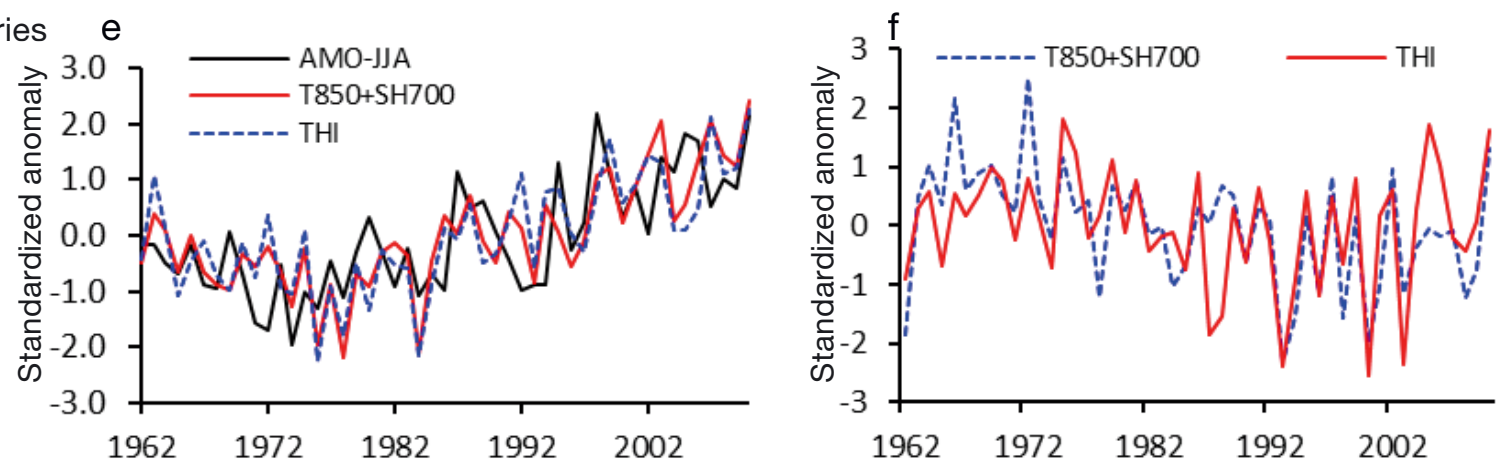

Fig. 5. Patterns of the first 2 canonical correlation analysis (CCA) pairs (left: CCA1, right: CCA2) of the combined predictors and temperature-humidity index (THI) in summer. $(\mathrm{a}, \mathrm{b}) \mathrm{THI}$; parentheses above panels: explained variance. (c,d) Specific humidity at $700 \mathrm{hPa}\left(\mathrm{SH} 700\left[\mathrm{~g} \mathrm{~kg}^{-1}\right]_{i}\right.$ contours), and air temperature at $850 \mathrm{hPa}\left(\mathrm{T} 850,{ }^{\circ} \mathrm{C}_{i}\right.$ colours) ; parentheses above panels: canonical correlation coefficient/explained variance. (e,f) Time series (standardized anomalies) associated with these 2 CCA pairs. For the CCA1 time series (left) the AMO index is also included

tern (Fig. S4) is very similar to the THI EOF1, also including the explained variance ( $87 \%$ for THI CCA1 vs. $89 \%$ for THI EOF1; see Fig. 3). This result shows that the THI increasing trend in Romania could be roughly justified by the increasing trend in the summer T850 covering the Romanian area, which is in agreement with the behaviour of other temperature extreme indices (Busuioc et al. 2015) and seems to be a reasonable mechanism from a physical point of view as presented above for WCT. However, the difference between the moments the shift occurred for the predictor (T850) and predictand (THI), respectively - even if small (about $5 \mathrm{yr}$ ), which from a statistical point of view could be considered quite reasonable - and the fact that the THI increase started earlier than the increase of T850, could lead to the 
conclusion that the real reason for the THI shift is not related to the T850 increase alone. Generally, the spatial distribution of the THI anomaly (with respect to the THI magnitude) follows the patterns of the T850 anomalies better than does WCT in wintertime: i.e. smaller values over the southwestern areas, similar to T850 anomalies, and a smaller spatial gradient over the Romanian territory. However, the small nucleus of higher positive THI anomalies over the southwestern area (Semenic-Tarcu Mountains) seems to have a different explanation, confirming the hypothesis presented above that the T850 alone could not justify all spatial and temporal characteristics of the THI variability. Analysing the linear trend in summer relative humidity over the same period, we found a nucleus of a significant increasing trend in this area (Fig. S2), showing that other additional factors could also influence the THI signal, as expected considering its definition, even if the T850 is the predominant factor inducing the general increasing trend. To prove this, the combination between T850 and SH700 was considered as a predictor. The CCA2 patterns representing the connection between T850 and THI (Fig. S4, right) also show a plausible physical mechanism: a dipole T850 structure (NE-SW oriented) is associated with a dipole THI structure with the same gradient type, similar to THI EOF2 (not shown) that confirms the fact that the second mode of the THI variability is induced by the second mode of the T850 variability (thermodynamic factor), compared to WCT, when the dynamic factor is second by order of importance to the thermodynamic one.

When the combination of T850 and SH700 is considered as predictor, both of the first 2 CCA pairs (Fig. 5a-d) show a strong connection and physically coherent mechanisms. The canonical correlation coefficient (0.93 for CCA1 and 0.65 for CCA2), THI CCA patterns and THI-explained variance are similar to those presented in Fig. S4 when the T850 alone is considered as the predictor. With respect to the T850 CCA patterns, they are also quite similar, but some different spatial details can be revealed: the nucleus of the highest T850 positive anomalies in the CCA1 is centred over Romania, compared to the north-position in the previous case; in the CCA2, a smaller area with positive T850 anomalies in the southwestern part is noted. The inclusion of the SH700 as a predictor does not yield supplementary information related to the THI climate signal (with respect to the general trend) in comparison with the previous case, but the time series associated with the CCA1 pair exhibit similar shifts around 1985 for both THI and the combined predictors (T850+SH700), similar to THI PC1; in the previous case, the THI upward shift started $5 \mathrm{yr}$ earlier than the increase of the predictor (T850), showing that the latter could not be the reason for the former. Therefore, we can state that the combination of T850 and SH700 can better explain the changes in various characteristics of THI variability, and this gives the results more physical coherence as summarised in the following. In the CCA1 pair, higher positive SH700 anomalies covering southwestern Romania (influencing mainly the mountain area, e.g. Semenic-Tarcu Mountains) - superimposed over a higher air temperature due to the highest positive T850 anomalies covering Romaniacould better justify the THI CCA1 pattern, as presented for the THI EOF1 (Fig. 3). The highest anomalies in mountain areas are explained by the effect of topography on air humidity. In the case of the CCA2 pair, the THI positive anomalies over the southeastern area are explained by higher positive SH700 anomalies covering this area, contributing to a slight deviation of the THI CCA2 pattern from a NE-SW gradient-like pattern due to a NE-SW gradient-like T850 pattern. The time series associated with the CCA1 show very coherent variation and suggest multi-decadal behaviour that is supported by a comparison with the AMO index (see Fig. 5e).

The predictor patterns of the 2 CCA pairs are similar to the patterns of their first 2 EOFs (not shown), indicating that the main modes of spatial and temporal THI variability in Romania are induced by the main modes of simultaneous variability of T850 and SH700 with a prevailing T850 that is not true for the WCT variability, which is given by regional patterns of the combination between the thermodynamic (T850) and dynamic (SLP) factors. On a multi-decadal time scale, variability in THI is modulated by the AMO. This result is in agreement with the behaviour of other indices of summer temperature extremes in Romania (Busuioc et al. 2015) and on the European scale (e.g. Della-Marta et al. 2007, Ionita et al. 2013). The time series associated with the CCA2 pair also exhibit a coherent year to year variation (Fig. 5f).

\section{CONCLUSIONS AND DISCUSSION}

As presented above, the purpose of this study was to identify the main spatial/temporal characteristics of variability for the 2 thermal stress indices on the one hand, and to understand the large-scale mechanisms responsible for these characteristics on the other. The main conclusions that can be drawn from this analysis are summarized in the following. 
(1) A significant upward trend in both stress indices is evident over the entire country, except for some areas for WCT, with a significant upward shift around the year 1987 for WCT and 1985 for THI. The rate of change (increase) is higher for THI. This signal is in agreement with the signal related to mean temperature and other temperature extremes analysed in Romania (Busuioc et al. 2010, 2015), but it is weaker for WCT compared to the winter mean temperature signal, due to the combined effect of the significant decreasing trend of wind speed over the entire extraCarpathian region and the upward trend in winter mean temperatures over some extra-Carpathian areas. This signal is also influenced by the nonlinear relationships between WCT and air temperature and wind speed. Another definition for the winter cold index could lead to a different result in terms of the signal magnitude. In summer, the effect of relative humidity on the THI trend is not significant due to no significant changes in this parameter over the analysed period. The upward shift found in this paper for the 2 thermal stress indices in about the same year (e.g. mid-1980s) is in agreement with the results presented by Vicente-Serrano et al. (2010), suggesting that the increasing drying trends detected in the SPEI global datasets over many land areas are due to a certain degree to the increasing temperature trend occurring in the mid-1980s. Therefore, our findings show that the increasing trends detected in the 2 thermal stress indices in Romania seem to be mainly a consequence of global warming, while other regional factors modulate the magnitude of this global signal that is well captured by the first CCA mode.

(2) The shift in the mean of the 2 thermal stress indices induced changes in the relative frequency of their extremes ('dangerous' values for human health). In this study, we only analysed the THI extremes. A significant increase in the frequency of extremely high THI values (> 80 units) after 1985 was revealed, showing an increased risk for human health in Romania after that year, especially in the southern and southeastern regions where the frequency was $>7 \%$. This behaviour is mainly due to an increase in the frequency of very high summer temperatures over these areas, in agreement with the results presented by Busuioc et al. (2015).

(3) The leading variability modes of both indices exhibit the same sign over the entire country and explain a high fraction of the total observed variance (89\% for THI and $73 \%$ for WCT), with some spatial differences between them, suggesting the existence of large-scale mechanisms responsible for this behaviour. These mechanisms are identified through the CCA technique, being represented by the first CCA mode. The second mode (explained variance of $3 \%$ for THI and $7 \%$ for WCT) presents a dipole structure, with some differences between the 2 indices in terms of pattern structure (NE-SW-oriented gradient for THI and intra/extra-Carpathian for WCT): we found that the reason for this behaviour is mainly given by thermodynamic factors in the case of THI (T850) and by dynamic factors (atmospheric circulation given by the SLP anomalies) in the case of WCT, as is shown by the second CCA mode.

(4) The main large-scale mechanisms responsible for the spatial and temporal behaviour of the 2 stress indices are given by the first CCA pair derived from the connection between the combination of T850 with SLP (thermodynamic and dynamic factors) for WCT (Fig. 4) and the combination of T850 with SH700 (thermodynamic factors) for THI (Fig. 5). In the case of WCT, the large-scale patterns for the first CCA mode reveal positive T850 anomalies over almost all of Europe (with a nucleus of the highest anomalies centered over Romania) simultaneously with a western zonal circulation (transporting warmer Atlantic air masses to Romania) that are associated with positive WCT anomalies over Romania. A significant increase in the frequency of such patterns since 1987 was found, justifying the upward shift of the WCT in Romania in the same period. Each of the large-scale predictors (T80, SLP) has a specific role: the general signal (upward trend) is induced by the T850 change, while the spatial distribution of change magnitude is induced by the atmospheric circulation change, modulated by NAO on a decadal time scale, the local factor represented by the Carpathians having an important additional role. In the case of THI, the main characteristics of changes (upward trend, shift in the mean and spatial distribution of the change magnitude) could be justified by the increasing trend in summer temperature at $850 \mathrm{hPa}$ simultaneously with an increasing trend in specific humidity at $700 \mathrm{hPa}$ over almost the entire country. On a decadal/multidecadal time scale, the THI variations are modulated by the AMO.

(5) The connection given by the first 2 CCA pairs is very strong for both indices, showing that these results can further be used in developing skilful statistical downscaling models (SDMs) to project future changes in the thermal stress indices in Romania (including their extremes) at local scales, producing high-resolution information useful in impact studies on human health and other domains.

(6) Finally, we can conclude that regional studies on changes in thermal stress indices (as presented 
here for Romania) are very important, considering the regional behaviour of changes in some climate variables included in their definition such as wind speed and relative humidity. It is known that temperature changes (as derived from observations as well as from future climate change scenarios) are quite homogeneous over large areas compared to changes in other climate variables. On the other hand, due to the poor performance of the regional climate models (RCMs, the most physically plausible sources of future climate change scenarios) in simulating wind speed, and their spatial resolution that is not always appropriate for local impact studies, no plausible projections of future changes regarding thermal stress indices are expected to be calculated directly from RCM simulations. A possible solution is to build skilful SDMs based on a strong statistical relationship between the local thermal stress indices and largescale climate variables well simulated by RCMs. Such a strong relationship was found in this study for Romania, and the next step is to build such SDMs.

Acknowledgements. This study was funded by the Executive Agency for Higher Education, Research, Development and Innovation Funding (UEFISCDI) through the research project CLIMHYDEX 'Changes in climate extremes and associated impact in hydrological events in Romania', code PNII-ID-2011-2-0073 (http://climhydex.meteoromania.ro). A. Dobrinescu acknowledges the support of the strategic grant POSDRU/159/1.5/S/137750, co-financed by the European Social Found within the Sectoral Operational Program Human Resources Development, 2007-2013. Two anonymous reviewers are acknowledged for their very useful comments, which improved the original manuscript.

\section{LITERATURE CITED}

Alexander LV, Zhang X, Peterson TC, Caesar J and others (2006) Global observed changes in daily climate extremes of temperature and precipitation. J Geophys Res 111:D05109, doi:10.1029/2005JD006290

Allen RG, Pereira LS, Raes D, Smith M (1998) Crop evapotranspiration-guidelines for computing crop water requirements. FAO Irrigation and Drainage Paper, No. 56. FAO, Rome

> Barnett TP, Preisendorfer R (1987) Origin and levels of monthly and seasonal forecast skill for United States surface air temperatures determined by canonical correlation analysis. Mon Weather Rev 115:1825-1850

Beniston M (2004) The 2003 heat wave in Europe: a shape of things to come? An analysis based on Swiss climatological data and model simulations. Geophys Res Lett 31: L02202, doi:10.1029/2003GL018857

Birsan MV, Marin L, Dumitrescu A (2013) Seasonal changes in wind speed in Romania. Romanian Rep Phys 65: 1479-1484, http://rrp.infim.ro/2013_65_4/A35.pdf

Birsan MV, Dumitrescu A, Micu DM, Cheval S (2014) Changes in annual temperature extremes in the Carpa- thians since AD 1961. Nat Hazards 74:1899-1910

Bojariu R, Paliu D (2001) North Atlantic Oscillation projection on Romanian climate fluctuations in the cold season. In: Brunet M, Lopez D (eds) Detecting and modelling regional climate change. Springer-Verlag, Berlin, Heidelberg, p 345-356

Busuioc A, Tomozeiu R (1998) Connection between maximum temperature variability in Romania and the large scale circulation. Romanian J Meteorol 5:29-38

$>$ Busuioc A, von Storch H (1996) Changes in the winter precipitation in Romania and its relation to the large scale circulation. Tellus Ser A Dyn Meteorol Oceanogr 48: 538-552

Busuioc A, von Storch H, Schnur R (1999) Verification of GCM generated regional seasonal precipitation for current climate and of statistical downscaling estimates under changing climate conditions. J Clim 12:258-272

Busuioc A, Chen D, Hellstrom C (2001) Temporal and spatial variability of precipitation in Sweden and its link with large-scale circulation. Tellus Ser A Dyn Meteorol Oceanogr 53:348-367

Busuioc A, Giorgi F, Bi X, Ionita M (2006) Comparison of regional climate model and statistical downscaling simulations of different winter precipitation change scenarios over Romania. Theor Appl Climatol 86:101-124

Busuioc A, Caian M, Cheval S, Bojariu R, Boroneant C, Baciu M, Dumitrescu A (2010) Climate variability and change in Romania. Pro Universitaria, Bucharest (in Romanian)

Busuioc A, Dobrinescu A, Birsan MV, Dumitrescu A, Orzan A (2015) Spatial and temporal variability of climate extremes in Romania and associated large-scale mechanisms. Int J Climatol 35:1278-1300

> Chase TN, Wolter K, Pielke RA Sr, Rasool I (2006) Was the 2003 European summer heat wave unusual in a global context? Geophys Res Lett 33:L23709, doi:10.1029/2006 GL027470

> Della-Marta PM, Luterbacher J, von Weissenfluh H, Xoplaki E, Brunet M, Wanner H (2007) Summer heat waves over western Europe 1880-2003, their relationship to largescale forcings and predictability. Clim Dyn 29:251-275

> Dikmen S, Hansen PJ (2009) Is the temperature-humidity index the best indicator of heat stress in lactating dairy cows in a subtropical environment? J Dairy Sci 92:109-116

Dole R, Hoerling M, Perlwitz J, Eischeid J and others (2011) Was there a basis for anticipating the 2010 Russian heat wave? Geophys Res Lett 38:L06702, doi:10.1029/2010GL 046582

> Donat MG, Alexander LV, Yang H, Durre I and others (2013) Updated analyses of temperature and precipitation extreme indices since the beginning of the twentieth century: the HadEX2 dataset. J Geophys Res Atmos 118: 2098-2118

> Dumitrescu A, Bojariu R, Birsan MV, Marin L, Manea A (2014) Recent climatic changes in Romania from observational data (1961-2013). Theor Appl Climatol, doi:10. 1007/s00704-014-1290-0

Efthymiadis D, Goodess CM, Jones PD (2011) Trends in Mediterranean gridded temperature extremes and largescale circulation influences. Nat Hazards Earth Syst Sci 11:2199-2214

> Gámiz-Fortis SR, Esteban-Parra MJ, Pozo-Vázquez D, Castro-Díez Y (2011) Variability of the monthly European temperature and its association with the Atlantic sea-surface temperature from interannual to multidecadal scales. Int J Climatol 31:2115-2140 
Haylock M, Goodess C (2004) Interannual variability of European extreme winter rainfall and links with mean large-scale circulation. Int J Climatol 24:759-776

Hoerling MP, Eischeid JK, Quan XW, Diaz HF, Webb RS, Dole RM, Easterling DR (2012) Is a transition to semipermanent drought conditions imminent in the US Great Plains? J Clim 25:8380-8386

Hurrell JW, van Loon H (1997) Decadal variations in climate associated with the North Atlantic Oscillation. Clim Change 36:301-326

Ionita M, Rimbu N, Chelcea S, Patru S (2013) Multidecadal variability of summer temperature over Romania and its relation with Atlantic Multidecadal Oscillation. Theor Appl Climatol 113:305-315

Kalnay E, Kanamitsu M, Kistler R, Collins W and others (1996) The NCEP/NCAR 40-year reanalysis project. Bull Am Meteorol Soc 77:437-471

Kendall MG (1975) Rank correlation methods. Charles Griffin, London

Kenyon J, Hegerl G (2008) Influence of modes of climate variability on global temperature extremes. J Clim 21: 3872-3889

Kulkarni A, von Storch H (1995) The effect of serial correlation on test of trend. Meteorol Z 4:82-85

Mann HB (1945) Nonparametric tests against trend. Econometrica 13:245-259

Mohan M, Gupta A, Bhati S (2014) A modified approach to analyze thermal comfort classification. Atmos Clim Sci 4: $7-19$

Nastos PT, Matzarakis A (2012) The effect of air temperature and human thermal indices on mortality in Athens, Greece. Theor Appl Climatol 108:591-599

> Orlowsky B, Seneviratne S (2012) Global changes in extreme events: regional and seasonal dimension. Clim Change 110:669-696

Osczevski R, Bluestein M (2005) The new wind chill equivalent temperature chart. Bull Am Meteorol Soc 86: 1453-1458

Palmer WC (1965) Meteorological drought. Research paper no. 45. Office of Climatology, US Weather Bureau, Washington, DC

Pettitt AN (1979) A non-parametric approach to the changepoint problem. Appl Stat 28:126-135

Sherwood SC, Huber M (2010) An adaptability limit to cli-

Editorial responsibility: Eduardo Zorita,

Geesthacht, Germany mate change due to heat stress. Proc Natl Acad Sci USA 107:9552-9555

Sneyers R (1975) Sur l'analyse statistique des séries d'observation. Note Technique, no. 143. WMO, Geneva

Spagnolo JC, De Dear RJ (2003) A human thermal climatology of subtropical Sydney. Int J Climatol 23: 1383-1395

Szentimrey T (1997) Statistical procedure for joint homogenization of climatic time series. Proc Seminar for Homogenization of Surface Climatological Data. Hungarian Meteorological Service, Budapest, p 47-62

Teodoreanu E, Bunescu I (2007) Thermal comfort. Present Environ Sustain Dev 1:134-142

> Tomozeiu R, Busuioc A, Stefan S (2002) Changes in seasonal mean of maximum air temperature in Romania and their connection with large-scale circulation. Int J Climatol 22: 1181-1196

Trenberth K, Fasullo J (2012) Climate extremes and climate change: the Russian heat wave and other climate extremes of 2010. J Geophys Res 117:D17103, doi:10.1029/ 2012JD018020

> van der Schrier G, Briffa KR, Jones PD, Osborn TJ (2006) Summer moisture variability across Europe. J Clim 19: 2818-2834

> Vicente-Serrano SM, Begueria S, Lopez-Moreno JI (2010) A multiscalar drought index sensitive to global warming: the standardized precipitation evapotranspiration index. J Clim 23:1696-1718

von Storch H, Zwiers F (1999) Statistical analysis in climate research. Cambridge University Press, Cambridge

Wilks SD (1995) Statistical methods in the atmospheric sciences. International Geophysics Series 59. Academic Press, New York

World Meteorological Organization (2004) Guidelines on biometeorology and air quality forecasts - human biometeorology. PWS-10. WMO/TD No. 1184. WMO, Geneva

> Xoplaki E, Gonzalez-Rouco JF, Luterbacher J, Wanner H (2004) Wet season Mediterranean precipitation variability: influence of large-scale dynamics and trends. Clim Dyn 23:63-78

Zorita E, Kharin V, von Storch H (1992) The atmospheric circulation and sea surface temperature in the North Atlantic area in winter: their interaction and relevance for Iberian precipitation. J Clim 5:1097-1108

Submitted: October 14, 2014; Accepted: May 5, 2015

Proofs received from author(s): August 10, 2015 